OPEN ACCESS

Edited by:

Philip G. Hahn,

University of Montana, United States

Reviewed by:

Adrienne Louise Godschalx Portland State University,

United States

Elena Gómez-Díaz,

Estación Biológica de Doñana (CSIC),

Spain

*Correspondence:

Mark D. Hunter

mdhunter@umich.edu

Specialty section:

This article was submitted to Behavioral and Evolutionary Ecology,

a section of the journal

Frontiers in Ecology and Evolution

Received: 22 August 2017 Accepted: 24 November 2017 Published: 08 December 2017

Citation:

Tao L, Hunter MD and de Roode JC (2017) Microbial Root Mutualists Affect the Predators and Pathogens of

Herbivores above Ground: Mechanisms, Magnitudes, and Missing Links.

Front. Ecol. Evol. 5:160 doi: 10.3389/fevo.2017.00160

\section{Microbial Root Mutualists Affect the Predators and Pathogens of Herbivores above Ground: Mechanisms, Magnitudes, and Missing Links}

\author{
Leiling Tao ${ }^{1}$, Mark D. Hunter ${ }^{2 \star}$ and Jacobus C. de Roode ${ }^{1}$ \\ 1 Department of Biology, Emory University, Atlanta, GA, United States, ${ }^{2}$ Department of Ecology and Evolutionary Biology, \\ University of Michigan, Ann Arbor, MI, United States
}

Tri-trophic interactions among plants, herbivores, and natural enemies of herbivores are common in nature, and are crucial components of trophic cascades and the dynamics of community composition. Plant traits are key determinants of the interactions between herbivores and their natural enemies aboveground, which in turn are affected by soil organisms. Recent years have seen a surge in studies of the interactions between below- and aboveground biota, including descriptions of how microbial root mutualists influence plant traits and herbivore performance. However, concomitant effects on the natural enemies of herbivores remain relatively poorly understood. Here, we review the currently available literature to assess how and when mutualistic root microbes impose significant indirect effects on the performance of predators and pathogens of insect herbivores. We focus on how root microbes influence predator attraction, on-plant foraging efficiency, and the quality of prey tissues. We also consider the underappreciated effects of microbial root mutualists on the growth, transmission, and virulence of insect pathogens. We end by discussing missing links and important directions for future research.

Keywords: above- and below-ground interrelationships, tri-trophic interactions, soil ecology, disease dynamics, mycorrhizal fungi, soil biota, plant-herbivore interactions, microbial root mutualist

\section{INTRODUCTION}

Understanding the mechanisms that underlie species interactions remains a central theme in ecology. Tri-trophic interactions among primary producers, herbivores and natural enemies of herbivores (predators, parasitoids, and pathogens) are common in nature, and are crucial mediators of trophic cascades, which can subsequently determine community dynamics, biodiversity, and ecosystem productivity (Hunter and Price, 1992; Polis et al., 2000; Borer et al., 2005). Therefore, understanding the factors that affect tri-trophic interactions is not only important for ecological research, but also critical for agricultural applications and conservation activities (Agrawal, 2000; Hunter, 2016). For example, natural enemies of herbivores are used extensively as agents of biological control, and understanding the factors that affect their efficiency can potentially optimize 
pest management and crop yield (Symondson et al., 2002). Furthermore, human disruption of tri-trophic interactions can lead to substantial consequences for biodiversity management. In the southeastern United States for instance, over-harvesting of blue crabs, predators of plant-grazing snails, may result in extensive die-offs of plants in salt marshes, leading to substantial losses in biodiversity and primary production (Silliman and Bertness, 2002).

Plant traits, such as nutrient content, size, and secondary chemistry, are key determinants of the interactions between herbivores and their natural enemies (Price et al., 1980; Vet and Dicke, 1992; Cory and Hoover, 2006); these plant traits provide the mechanistic basis by which tri-trophic interactions occur. In turn, these same plant traits respond to the complex interactions that take place between plants and soil organisms belowground. Both root mutualists (e.g., rhizobia, mycorrhizal fungi, and detritivores) and root antagonists (e.g., herbivores, parasites) can strongly alter the fundamental plant traits that drive tri-trophic interactions above ground (Smith and Read, 2008; Chapin et al., 2011). As a consequence, recent work has begun to explore how belowground biota influence tri-trophic interactions aboveground through generating variation in plant traits (Hunter, 2016; Rasmann et al., 2017). Recent years have seen a surge in studies of the interactions between below- and aboveground biota, demonstrating that belowground organisms have major effects on aboveground ecological processes, including plant physical and chemical traits, plant performance, herbivore and pollinator performance, and their recruitment (Van der Putten et al., 2001; Wardle et al., 2004; Bezemer and van Dam, 2005; Schädler and Ballhorn, 2016). However, our understanding of the role of belowground interactions between plants and other organisms on aboveground tri-trophic interactions remains in its infancy (Rasmann et al., 2017). Most of the limited work to date has focused on microbial root mutualists, their impacts on plant traits, and how these traits generate tri-trophic interactions between plants, arthropod herbivores, and arthropod natural enemies. Here, we summarize this work, while adding in some recent studies of how the performance of the pathogens of herbivores responds to variation in plant traits introduced by microbial root mutualists. Our goals are (1) to summarize recent progress and identify the mechanisms by which belowground mutualists alter predation and pathogens pressure on herbivores aboveground; and (2) to point out missing links and important directions for future research. Under "mechanisms" we focus here on the plant traits that mediate the tri-trophic interactions. We also describe any associated changes that those plant traits engender in the behavior of herbivores or enemies that translate to modify herbivore mortality.

As we will show throughout the paper, this field is still in its infancy with a small number of published studies focusing on a handful of study systems. As a consequence, the mechanisms that we review here are by no means a complete accounting of the vast diversity and context-dependency of below-aboveground interactions. Rather, our main purpose is to demonstrate that belowground root mutualists can have major impacts on aboveground tri-trophic interactions through a variety of trait-based pathways, and that many exciting questions await future research.

\section{FOCUS OF THE REVIEW}

Our purpose here is not to review the myriad of ways in which microbial root mutualists influence plant traits and plant ecology. There are reviews, book chapters, and entire texts already available on these topics (Heath and Tiffin, 2007; Smith and Read, 2008; Hunter, 2016). Instead, we focus specifically on how root mutualists influence the tritrophic interactions among plants, arthropod herbivores and their enemies (arthropod predators or parasitoids and agents of disease). Arthropod herbivores represent one of the largest and most diverse groups of metazoans on earth, and play essential roles in determining food web stability, community composition, diversity, and ecosystem functioning (Speight et al., 2008). Arthropod herbivores sustain a great diversity of enemies including predators, parasitoids and pathogens. At the same time, plants form associations with many organisms in the soil, from antagonistic organisms such as root herbivores and pathogens to mutualistic organisms including arbuscular mycorrhizal fungi (AMF), rhizobia, symbiotic bacteria, detritivores, and decomposers (Van der Putten et al., 2001; Wardle et al., 2004; Bezemer and van Dam, 2005; Pineda et al., 2013a; Schädler and Ballhorn, 2016). Here, we focus primarily on the beneficial microbes that associate with roots and summarize our current understanding of how they affect the impacts of predators and pathogens above ground. Again, the mechanistic basis underlying these tri-trophic interactions is generally the changes in plant traits mediated by plant associations with root microbes; we focus on the traits that dominate the literature on tri-trophic interactions, particularly primary and secondary metabolites and plant morphology. While we note briefly the simple but pervasive effects of mutualistic microbes on plant size and vigor, such effects have been reviewed recently (Rasmann et al., 2017) and are not a major focus here. Additionally, while belowground mutualists can affect the composition of enemy communities above ground (Schreck et al., 2013), we focus here on the performance and population dynamics of predators and pathogens because their links to chemical plant traits are much more firmly established. We first consider predators and parasitoids of arthropod herbivores, which belowground mutualists influence indirectly by changing the plant traits that determine long-distance plant attractiveness, on-plant foraging by enemies, and the nutritional quality of prey. Second, we consider how microbial root mutualists influence herbivore pathogens through their indirect effects on pathogen growth, transmission and virulence. We searched ISI Web of Science and Google Scholar using the keys words "belowground aboveground tri-trophic interactions" and their variants to find relevant publications. Subsequently, we read the literature cited by these papers to find and compile all other relevant studies. Table 1 provides a full summary of existing studies and Figure 1 provides three representative examples for a predator, parasitoid, and pathogen, respectively. 
TABLE 1 | Published studies of the effects of belowground organisms on aboveground tri-trophic interactions.

\begin{tabular}{|c|c|c|c|}
\hline Study & Type of belowground organism & Type of enemy & Response \\
\hline \multicolumn{4}{|c|}{ PARASITOIDS AND PREDATORS: PREY LOCALIZATION } \\
\hline Guerrieri et al., 2004 & AMF & Parasitoid & $(+)$ preference \\
\hline Soler et al., 2007b & Root herbivore & Parasitoid & $(-)$ avoidance \\
\hline Hoffmann et al., 2011b & AMF & Predator & $(+)$ preference \\
\hline Schausberger et al., 2012 & AMF & Predator & $(+)$ preference \\
\hline Battaglia et al., 2013 & Non-AMF fungi & Parasitoid, Predator & $(+)$ preference \\
\hline Kruidhof et al., 2013 & Root herbivore & Parasitoid & $(-)$ avoidance in C. glomerata; $(+)$ preference in C. rubecula \\
\hline Pineda et al., 2013b & Rhizobia & Parasitoid & $(-)$ avoidance \\
\hline Godschalx et al., 2015 & Rhizobia & Predator & $(-)$ avoidance \\
\hline Pangesti et al., 2015 & Rhizobia & Parasitoid & $(+)$ preference \\
\hline \multicolumn{4}{|c|}{ PARASITOIDS AND PREDATORS: PREY QUALITY } \\
\hline Masters et al., 2001 & Root herbivore & Predator & $(+)$ higher abundance \\
\hline Gange et al., 2003 & AMF & Parasitoid & $(+,-, 0)$ on parasitism rate, depending on the fungal species \\
\hline Bezemer et al., 2005 & Soil microorganism and nematode & Parasitoid & $(+)$ nematodes increase parasitoid survival, size and female ratio \\
\hline Soler et al., 2005 & Root herbivore & Parasitoid & $(-)$ reduced size and increased development time \\
\hline Hempel et al., 2009 & AMF & Parasitoid & $(+)$ increased parasitism rate and size, reduced development time \\
\hline Megías and Müller, 2010 & Detritivore and root herbivore & Parasitoid & $(+)$ detritivores increased parasitism rate and abundance \\
\hline Hoffmann et al., 2011c & AMF & Predator & $(+)$ higher population growth rate \\
\hline Johnson et al., 2011 & Earthworm & Parasitoid & $(+)$ higher abundance \\
\hline Katayama et al., 2011 & Rhizobia & Predator & $(+)$ higher abundance and species richness \\
\hline Wooley and Paine, 2011 & AMF & Parasitoid & $(+, 0)$ on abundance depending on AMF strain \\
\hline Battaglia et al., 2013 & Non-AMF fungi & Predator & $(+)$ on development rate, $(0)$ on birth rate \\
\hline Moon et al., 2013 & AMF & Parasitoid & $(+,-)$ on percent parasitized depending on herbivore species \\
\hline Kruidhof et al., 2013 & Root herbivore & Parasitoid & (0) no effects on development time and adult weight \\
\hline Pineda et al., 2013b & Rhizobia & Parasitoid & $\begin{array}{l}(-, 0) \text { no effects on development time, survival or weight; negative effects } \\
\text { on abundance }\end{array}$ \\
\hline Schreck et al., 2013 & AMF & Predator & $(+)$ on predator density \\
\hline Ueda et al., 2013 & AMF & Predator & $(+,-)$ on predator abundance depending on the sampling date \\
\hline Pangesti et al., 2015 & Rhizobia & Parasitoid & (0) on developmental time, survival, weight \\
\hline \multicolumn{4}{|l|}{ PATHOGENS } \\
\hline Tao et al., 2015 & AMF & Pathogen & $\begin{array}{l}(+,-, 0) \text { on parasite virulence and sporeload depending on plant species } \\
\text { and AMF colonization level }\end{array}$ \\
\hline
\end{tabular}

(+), (-), and (0) signify positive, negative, and neutral effects of belowground organisms on traits of the enemies, respectively. AMF, arbuscular mycorrhizal fungi.

\section{MUTUALISTIC MICROBES BELOW GROUND AFFECT PREDATORS AND PARASITOIDS OF HERBIVORES ABOVE GROUND}

Here, we separate the interactions between herbivores and their parasitoids and predators into three stages: a prey localization stage, during which enemies actively forage for herbivores over long distances; an on-plant foraging stage, during which plant physical traits mediate enemy foraging efficiency; and an after-contact stage, when enemies consume and/or reproduce in herbivore tissues, the quality of which determines enemy performance. Critically, the mechanisms underlying all of these interactions are based on variable plant traits (morphology, chemistry, physiology), that are subject to modifications by microbial root mutualists. We encourage readers to explore a recent paper (Rasmann et al., 2017), which also considers how microbial traits (microbial volatiles) may influence tri-trophic interactions above ground, and (b) includes a review of indirect defenses below ground, which we do not consider here.

\section{Prey Localization}

Predators and parasitoids must locate their herbivorous prey before attacking those prey items. Prey location by invertebrate predators mainly occurs through visual and olfactory cues, which are strongly affected by plant morphology and chemical traits (the mechanisms). Plant size and architectural complexity are key determinants of foraging efficiencies of parasitoids, with increases in size and complexity reducing per capita foraging efficiency (Cloyd and Sadof, 2000; Gingras and Boivin, 2002), while increasing the diversity of alternative prey (Lawton, 1983; Fowler, 1985). Consequently, when oxeye daisies (Leucanthemum vulgare) grow larger through association with AMF, rates of parasitism of the leaf miner Chromatomyia 

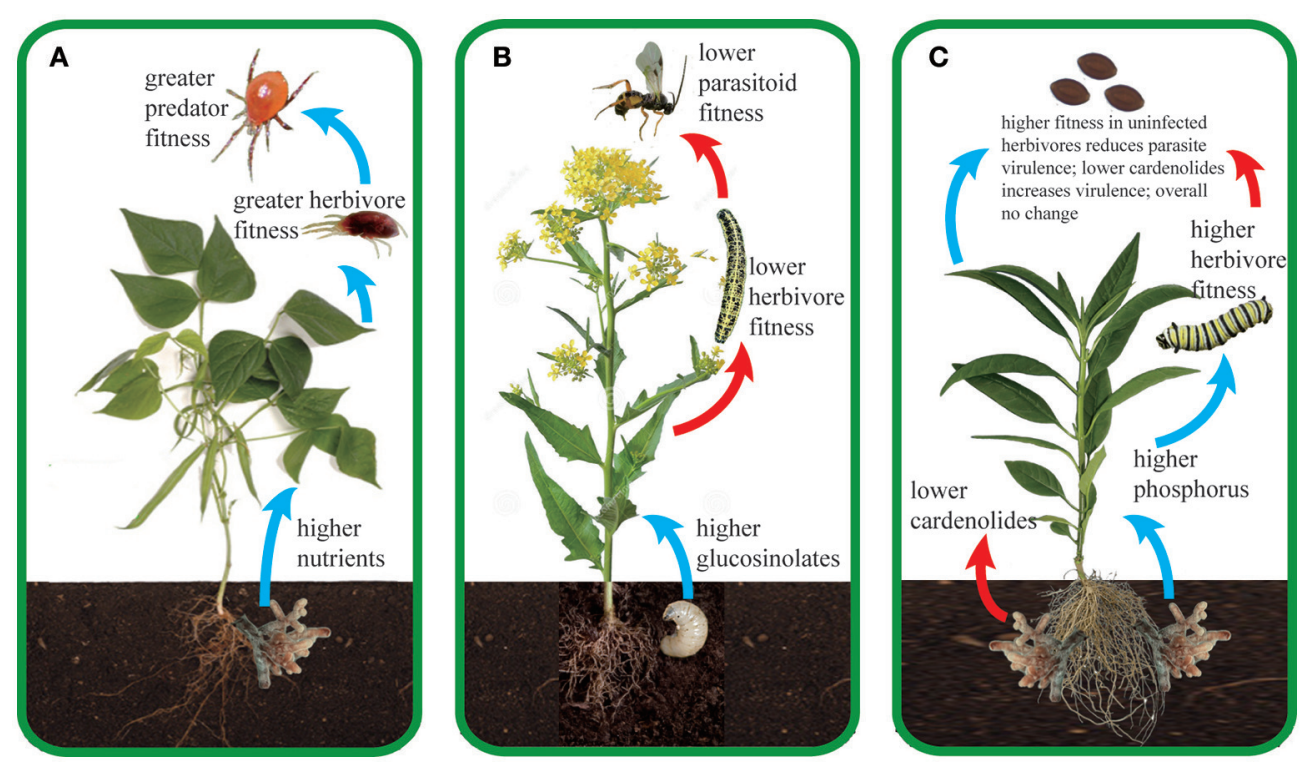

FIGURE 1 | Representative examples of how root mutualists (A,C) and root antagonists (B) can influence tri-trophic interactions aboveground. Blue and red arrows signify positive and negative effects on the next trophic level, respectively. (A) Associations with the arbuscular mycorrhizal fungus (AMF) Glomus mosseae can lead to higher macronutrient (phosphorus and potassium) content in bean plants (Phaseolus vulgaris), which subsequently results in greater oviposition rate, growth rate, and shorter doubling time of the herbivorous spider mite Tetranychus urticae (Hoffmann et al., 2009). Higher quantity and quality of T. urticae directly translate into higher fitness and population growth rate of the predatory mite Phytoseiulus persimilis (Hoffmann et al., 2011c). Female P. persimilis preferentially select eggs of T. urticae that are reared on AMF-associated bean plants due to their higher quality (Hoffmann et al., 2011b); additionally, they can "smell" AMF-associated plants because AMF increase the production of $\beta$-ocimene and $\beta$-caryophyllene in T. urticae-infested plants (Schausberger et al., 2012). Although AMF increase performance of the herbivore T. urticae, higher population growth of $P$. persimilis and higher plant tolerance compensate for the negative effects of the herbivores, leading to higher seed production in the bean plants (Hoffmann et al., 2011a). Additionally, P. persimilis increases root AMF colonization rates, which may create a positive feedback among AMF, plants and predators in this important agricultural system (Hoffmann et al., 2011a). (B) Infestation of black mustard (Brassica nigra) roots by cabbage fly larvae (D. radicum) increases sinigrin concentrations (a type of glucosinolate) in plant shoots, which negatively affects fitness of cabbage butterfly larvae ( $P$. brassicae) and their parasitoid wasps Cotesia glomerata (Soler et al., 2005). As a result, both P. brassicae and C. glomerata have evolved to avoid plants with root herbivores (Soler et al., 2007a, 2010; Kruidhof et al., 2013), possibly through avoiding sulfur volatile compounds that are emitted by the plants after attack by the root herbivore (Soler et al., 2007a). Such avoidance behavior can increase foraging efficiency of $C$. glomerata on plants surrounded by root-infested plants, because the volatiles may provide a contrast within the background blends emitted by plants without root herbivory (Soler et al., 2007b). (C) AMF-milkweed Asclepias spp. - monarch butterfly Danaus plexippus - protozoan parasite Ophryocystis elektroscirrha For monarch butterflies (Danaus plexippus), milkweed (Asclepias spp.) secondary chemicals called cardenolides reduce growth of the protozoan parasite Ophryocystis elektroscirrha and increase the lifespan of infected butterflies (de Roode et al., 2008, 2011; Sternberg et al., 2012; Gowler et al., 2015). In both uninfected and infected butterflies, nutrients such as nitrogen and phosphorus positively affect monarch larval performance (Tao and Hunter, 2012; Tao et al., 2014, 2015). Since associations with AMF can significantly change cardenolide and nutrient concentrations across milkweed species (Vannette and Hunter, 2011; Vannette et al., 2013; Tao et al., 2015, 2016), they indirectly affect parasite virulence and monarch tolerance (Tao et al., 2015). For example, in A. curassavica (shown here), AMF increase foliar P concentrations while decreasing foliar cardenolide concentrations, yielding overall neutral effects on the lifespan of infected butterflies (Tao et al., 2015).

syngenesiae by the wasp Diglyphus isaea decline (Gange et al., 2003).

Plants recruit predators and parasitoids through indirect defense mechanisms, such as food rewards (e.g., extrafloral nectars), shelters (domatia), and volatile organic compounds (VOCs) (Dicke, 1999; Agrawal, 2000) that can attract predators and parasitoids over long distances. Because allocation to domatia and extra-floral nectaries depend on both nutrient status and plant size (Frederickson et al., 2012; Heil, 2015), microbial root mutualists are likely to influence the quality of such food and shelter rewards for predators and parasitoids (Heil et al., 2001; Radhika et al., 2008; Holland et al., 2009). Notably, microbial root mutualists receive sugar from their plant hosts, in exchange for mineral nutrients and water. The carbon costs associated with hosting microbial mutualists may explain why some plants reduce their rewards to enemies aboveground when associated with root microbes. For example, in Vicia faba, association with AMF reduces extrafloral nectaries, which may result in reduced protection by ants against herbivores (Laird and Addicott, 2007). Similarly, rhizobia reduce extrafloral nectar production by lima beans (Phaseolus lunatus), leading to fewer ants attracted to rhizobia associated plants (Godschalx et al., 2015). Here, the mechanistic basis underlying the tri-trophic interaction above ground appears to be a tradeoff in plant resource allocation between root mutualists and indirect defense rewards.

Compared to the other mechanisms described here, there is much more evidence in support of the hypothesis that microbial root mutualists alter the expression by plants of VOCs (Rasmann et al., 2017). For example, in sweet wormwood Artemisia annua, association with AMF increases emissions of the monoterpene limonene and artemisia ketone (Rapparini et al., 2008), which attract both herbivores and their natural enemies (Wei et al., 
2008; Rodríguez et al., 2011). Similarly, the root fungal endophyte Acremonium strictum changes the terpene composition in volatiles of tomato Lycopersicon esculentum (Jallow et al., 2008). In Plantago lanceolata, AMF reduce herbivore-induced sesquiterpenes, chemicals that recruit parasitoids after herbivory (Fontana et al., 2009). In short, since the composition of volatile compounds is key to predator/parasitoid attraction, these mutualist-induced changes in VOC emission likely represent dominant mechanisms by which microbial root mutualists influence tri-trophic interactions aboveground.

We should note that belowground mutualists may affect the composition of plant VOCs aboveground through multiple mechanisms. First, mutualistic microbes may alter the production and emission of plant VOCs by modifying nutrient availability. For example, higher nutrient (nitrogen, phosphorus and potassium) concentrations in Eucalyptus tereticornis increase emission of the volatile terpene 1,8-cineole, which subsequently attracts more predators and parasitoids (Low et al., 2014). Similarly, supplementing A. annua with phosphorus (P) largely mimics the effects of AMF on VOC production (Rapparini et al., 2008).

In contrast, greater attraction of aphids to beans, V. faba, associated with AMF is not due to changes in $\mathrm{P}$ availability (Babikova et al., 2014). Rather, microbial mutualists may influence expression of the jasmonic acid (JA), salicylic acid (SA), cytokinin, and abscisic acid (ABA) pathways (Pineda et al., 2013a), all of which influence the production of VOCs (Ballhorn et al., 2013; Pineda et al., 2013b). For example, by interfering with the JA pathway in Arabidopsis thaliana, rhizobia change the induction of plant VOCs by the aphid Myzus persicae, thereby reducing attraction of the parasitoid wasp Diaeretiella rapae (Pineda et al., 2013b). Moreover, mycorrhizal mycelia often connect the roots of neighboring plants (Francis and Read, 1984), such that mycorrhizal fungi may transmit signals among plants and thereby affect enemy attraction by neighboring plants (Song et al., 2010). For example, bean plants ( $V$. faba) detect aphid herbivory of their neighbors through mycorrhizal fungal connections and alter their own production of VOCs (specifically increasing methyl salicylate), so that parasitoids are more attracted to them compared to plants without belowground mycelial connections (Babikova et al., 2013).

While evidence is accumulating that microbial root mutualists play an important role in mediating the production of VOCs and subsequent enemy foraging behavior, their impact is system-specific. Sometimes the effects can be large; in the tomato L. esculentum, for instance, association with the AMF Glomus mosseae results in a two-fold increase in parasitoid attraction, even in the absence of herbivores (Guerrieri et al., 2004). In other circumstances, effects are harder to detect. For example, attraction of the predatory mite Phytoseiulus persimilis to bean plants (Phaseolus vulgaris) appears unaffected by association with AMF, at least during the first 3 days of spider mite (Tetranychus urticae) infestation (Schausberger et al., 2012). This variation in effect sizes may be due to differences in responses of plants to their root mutualists, and/or interspecific variation in responses of enemies to plant VOCs (Leitner et al., 2010; Kruidhof et al., 2013). We return to this challenge of variability in the section on Missing Links (below).

We emphasized above that changes to plant chemical and physical traits provide the mechanistic basis underlying the effects of microbial root mutualists on the enemies of herbivores above ground. Consequently, when microbial root mutualists change more than one physical or chemical trait simultaneously, predicting the net outcome for tri-trophic interactions can be a major challenge. For example, with regard to the oxeye daisy-leaf miner-parasitoid interaction described previously, association with AMF increases plant size, which reduces parasitism of the leaf miner by the parasitoid due to lower prey location efficiency (Gange et al., 2003). However, in bean plants (P. vulgaris), AMF increase the emission of VOCs that can attract enemies (Schausberger et al., 2012). Thus, if both of these processes were to operate in the same system, their relative strength would determine whether the net effect of AMF was an increase or a decrease in parasitism. At this time, there are almost no data describing effects of root mutualists on tri-trophic interactions under multiple changes in plant traits. As we note under Missing Links (below) future studies are urgently needed to help understand the species specificity of plant responses to belowground mutualists, and incorporate simultaneously their effects on multiple plant traits that mediate herbivore-enemy interactions.

\section{On-Plant Foraging Efficiency}

After a predator or parasitoid successfully locates a plant with prey, it needs to find its prey on the plant and attack it. This foraging process is also influenced strongly by physical and chemical plant traits that can be altered by microbial root mutualists. For instance, glandular trichomes, hairs with secretory cells, can directly intoxicate parasitoids (Kennedy, 2003) and/or impede enemy walking speed (Krips et al., 1999), resulting in lower foraging efficiency. However, for some specialist predators, sticky trichomes may trap insect cadavers, thereby attracting more predators (Krimmel and Pearse, 2013). Similarly, plant epicuticular waxes can decrease attachment of predatory insects and parasitoids to the plant surface and disrupt their feeding (Eigenbrode, 2004). Critically, belowground mutualists affect the expression of both glandular trichomes and epicuticular waxes (Goicoechea et al., 2004; Copetta et al., 2006), providing additional mechanistic pathways by which microbial root mutualists may influence tri-trophic interactions. Unfortunately, to our knowledge, no study has explored explicitly the links among root mutualists, plant trichomes/waxes, and the efficiency of enemy foraging aboveground. Again, such work is urgently needed.

\section{Prey Quality}

Microbial root mutualists alter the nutrient and toxin concentrations of herbivore tissues (Hunter, 2016), providing an additional mechanistic pathway by which root mutualists mediate tri-trophic interactions aboveground. Prey quality is important in determining the fitness of predators and parasitoids. Compared to herbivorous insects, predatory arthropods and parasitoids have higher body nitrogen $(\mathrm{N})$ and $\mathrm{P}$ contents, so 
increases in plant nutrition can lead to greater performance of predators and parasitoids (Denno et al., 2002; Wurst and Jones, 2003; Maure et al., 2016). Therefore, by affecting plant nutritional status, root microbes belowground can indirectly affect predators and parasitoids aboveground. For example, in the presence of AMF, the predatory mite $P$. persimilis has a greater oviposition rate and shorter development time due to the higher quality of its prey, the two-spotted spider mite Tetranychus urricae (Figure 1A) (Hoffmann et al., 2011c). Additionally, plant nutrient status often affects herbivore size, which in turn influences predator and parasitoid performance (Hunter, 2016). When the aphid Rhopalossiphum padi feeds on plants infested with free-living and root-feeding soil nematodes, it grows significantly larger than when feeding on plants without soil nematodes, resulting in higher emergence success of its parasitoid Aphidius colemani (Bezemer et al., 2005).

Root associates may also alter the quality of prey for natural enemies by their impacts on plant secondary chemicals, which occur both passively in the hemolymph and midgut of herbivores, or may be sequestered in herbivore tissues (Nishida, 2002; Lampert et al., 2011). For example, plant glucosinolates occurring within herbivore prey negatively affect a wide range of parasitoids (Gols and Harvey, 2009). While we focus here on root microbial mutualists, we note that there is now abundant evidence of root-feeding herbivores influencing the chemistry of plant tissues above ground, with subsequent effects on herbivore and enemy performance (Hunter, 2016). For example, root-feeding cabbage fly larvae (Delia radicum) induce higher glucosinolate concentrations in Brassica nigra. In turn, higher glucosinolate concentrations lead to longer development time and smaller size of both cabbage butterfly caterpillars (Pieris brassicae) and their parasitoid wasps, Cotesia glomerata (Figure 1B) (Soler et al., 2005).

Importantly, plant secondary metabolites also affect herbivore immune defenses against predators and parasites (Smilanich et al., 2009; Lampert, 2012). High concentrations of plant secondary metabolites tend to reduce immune defenses, probably because of their negative effects on insect growth rate and reduced allocation to immune functions. For example, hydrolysable tannins in quaking aspen (Populus tremuloides) correlate negatively with immune defense in the autumnal moth Epirrita autumnata (Haviola et al., 2007), and high iridoid glycoside concentrations in $P$. lanceolata compromise immune responses in the common buckeye caterpillar Junonia coenia (Smilanich et al., 2009). Lower immune defense can lead to higher performance of parasitoids (Reudler et al., 2011; Kos et al., 2012). While microbial root mutualists affect the expression of these (and other) secondary chemicals (tannins, Beyeler and Heyser, 1997; iridoid glycosides, Bennett et al., 2009), to our knowledge, no study has directly explored effects of soil organisms on host insect immunity through changes in secondary chemistry.

\section{SOIL ORGANISMS AFFECT PATHOGENS OF HERBIVORES}

Many of the same mechanistic pathways (chemical and physical traits) by which microbial root mutualists impact the efficacy of predators and parasitoids may also affect the pathogens of herbivores. Herbivorous insects are host to a wide diversity of disease agents, including protozoans, bacteria, and viruses. As with parasitoids and predators, the performance of herbivore pathogens is affected by both plant nutritional and secondary chemicals, and therefore influenced by belowground root mutualists. However, the effects of increased concentrations of nutritional chemicals on pathogens are not as readily predicted as they are for other types of natural enemy. This is because increases in plant nutritional quality can result in increased resources for pathogens, but can also result in improved host immunity (Povey et al., 2009; Cotter et al., 2011). Therefore, when associations with soil mutualists result in higher plant nutrient concentrations, any subsequent increases in rates of pathogen replication may be counteracted by concomitant increases in host immunity.

With respect to secondary metabolites, multiple classes of chemicals inhibit insect pathogens (Cory and Hoover, 2006). For example, plant pyrrolizidine alkaloids reduce the production of entomopathogenic nematodes feeding within woolly bear caterpillars, Grammia incorrupta (Gassmann et al., 2010). Likewise, when chlorogenic acid in tomatoes is oxidized to chlorogenoquinone, it binds covalently to occlusion bodies of the baculovirus HzSNPV and reduces their infectivity in the corn earworm Helicoverpa zea (Felton and Duffey, 1990). Similarly, in monarch butterflies (Danaus plexippus), the growth of its specialist protozoan parasite (Ophryocystis elektroscirrha) correlates negatively with foliar concentrations of cardenolides, toxic secondary chemicals in milkweed host plants (de Roode et al., 2008, 2011; Sternberg et al., 2012). In addition, the lifespan of infected butterflies correlates positively with cardenolides, a result of reduced parasite growth as well as increased monarch tolerance of infection (de Roode et al., 2008, 2011; Sternberg et al., 2012; Gowler et al., 2015). Because AMF associations belowground change the composition and concentration of milkweed cardenolides aboveground, AMF have substantial effects on monarch-parasite dynamics across milkweed hosts (Tao et al., 2015), an interaction across four biological kingdoms (Figure 1C).

When the infective stages of pathogens are released on plants, many plant traits affect their survival and persistence. For example, plant architecture, leaf form and color affect the amount of UV that is reflected onto the leaf surface, and thereby affect the survival of insect baculoviruses, which are sensitive to UV light (Hunter-Fujita et al., 1998; Cory and Hoover, 2006). Additionally, phylloplane microclimate and physiochemical properties affect pathogen infectivity and persistence (Der Geest, 2000). Currently, there remains limited information on whether microbial root mutualists affect these physical plant traits; if they do, belowground mutualists may have significant indirect effects on pathogen survival and persistence prior to infection.

Intraspecific variation in plant nutritional and secondary chemistry induced by root mutualists can also affect the foraging and oviposition behaviors of insect herbivores, with implications for herbivore contact rates and disease transmission. For example, AMF-associated Baccharis halimifolia and prairie $\mathrm{C}_{3}$ graminoids experience higher herbivory than do plants without AMF (Moon et al., 2013; Kula and Hartnett, 2015), 
which may translate to higher rates of disease transmission among herbivores due to higher host density. Since transmission rate is fundamental to determining host-pathogen dynamics, understanding how microbial root mutualists affect disease transmission is important in both natural insect populations and in microbial biological control (Hunter, 2016). Although herbivore density and foraging behavior on individual plants clearly affect pathogen transmission (Parker et al., 2010), explicit links among root mutualists, plant traits, herbivore density, and disease transmission have yet to be made in the literature.

As we noted above for predators and parasitoids, soil mutualists affect multiple plant traits simultaneously, generating multiple mechanistic pathways by which root microbes influence tri-trophic interactions above ground. As with other enemies, the overall impact of root mutualists on disease dynamics will depend on the relative strength of each mechanistic pathway. Following the example of the monarch butterfly and its protozoan parasite described above, while cardenolides (secondary chemicals) reduce parasite numbers and increase the lifespan of infected butterflies (de Roode et al., 2008, 2011; Sternberg et al., 2012), macronutrients such as $\mathrm{N}$ and $\mathrm{P}$ also increase monarch performance (Tao and Hunter, 2012; Tao et al., 2014, 2015). Since associations with AMF change macronutrients and cardenolides simultaneously in milkweed leaves (Vannette and Rasmann, 2012; Tao et al., 2016), the net effects of AMF on butterflyparasite interactions are best explained by the combined changes in milkweed $\mathrm{P}$ and cardenolide concentrations (Figure 1C) (Tao et al., 2015). Net effects on monarchs vary from positive, through neutral, to negative, depending on how particular milkweed species respond phenotypically to their root microbial mutualists.

\section{MISSING LINKS}

The last 15 years have seen an increase in the number of studies investigating indirect effects of belowground biota on aboveground tri-trophic interactions (Rasmann et al., 2017). As illustrated by our review, microbial root mutualists affect aboveground predators, parasitoids, and pathogens through a diverse set of mechanistic pathways, based on changes in the chemical and physical traits of plants engendered by root microbes. Specifically, chemical and morphological changes in plants alter the attractiveness of herbivore-infested plants to predators, the efficiency of their on-plant foraging behaviors, and the quality of herbivore tissues for enemy consumers. In addition, microbial root mutualists can change the efficacy of pathogens that attack herbivores above ground through their combined effects on plant morphology and plant nutritional and defensive chemistry.

However, the mechanisms of interaction documented to date (changes in plant nutritional quality, plant morphology, and plant secondary chemistry) represent a small subset of the potential pathways by which belowground biota more generally may influence tri-trophic interactions aboveground (van der Heijden et al., 1998; Smith and Read, 2008; Reinhart et al., 2012; Hunter, 2016; Rasmann et al., 2017). Unfortunately, the overall number of studies on this topic remains critically small, and most are focused on a few systems; as a result, significant knowledge gaps remain. Here, we highlight several of these gaps, in the hope that future studies will advance our understanding of these below-aboveground interactions.

(1) In reviewing this literature, we have been struck repeatedly by the difficulty of finding any generality in the magnitude and direction of effects of microbial root mutualists on tri-trophic interactions aboveground. One likely culprit is simply the small number of studies that have been conducted to date on this topic (Table 1); generality is hard to achieve when sample size is low. A major goal of this review is to support the call (Rasmann et al., 2017) for a concerted effort to understand how belowground organisms influence multi-trophic interactions aboveground. Pervasive effects of root biota on plant traits above ground are now well-documented (Hunter, 2016), but concomitant changes in the efficacy of predators and pathogens need much more attention.

Certainly, there is a clear need to look beyond effects mediated by mycorrhizal fungi and $\mathrm{N}$-fixing symbionts, which still dominate the literature in this field. This is a two-part process: first documenting the diverse changes in plant physiology, chemistry, and morphology induced by different kinds of soil biota; second, linking explicitly these changes in plant traits to the expression of tri-trophic interactions. There has been substantial progress in the first of these, and minimal progress in the second. For example, evidence is accumulating that the rhizosphere is replete with other kinds of mutualistic microbe, including root endophytes and growth-promoting bacteria, which affect aboveground plant-herbivore interactions (Jaber and Vidal, 2010; Brunner et al., 2015). Similarly, soil macro-organisms, including dung beetles and springtails, are important ecosystem engineers that alter concentrations of the plant nutrients that are important to aboveground herbivores (Johnson et al., 2015c). Beyond root mutualists, there are well-characterized effects of root antagonists (root herbivores, pathogens, competitors) on plant phenotypic traits (Hunter, 2016), many of which are candidates for driving complex ecological interactions aboveground (Wyckhuys et al., 2017). Unfortunately, how these diverse soil biota influence tri-trophic interactions aboveground, either individually or interactively, remains largely unknown.

Beyond just a paucity of studies, a related barrier to generality is the apparent contingency in the responses of plant traits, and therefore tri-trophic interactions, to soil organisms (Barber et al., 2013). Within the microbial root mutualists, there have been several efforts to establish patterns among plant phenotypic responses based on plant phylogeny and life-history (Reinhart et al., 2012; Vannette et al., 2013). Unfortunately, the effects of microbial root mutualists on plant phenotype and herbivore performance seem to vary substantially among species of plant, species of microbe, species of herbivore, and environmental conditions (Garmendia et al., 2004; Gehring and Bennett, 2009; Grman, 2012; Grman and Robinson, 2012; Barber et al., 2013). To complicate matters further, the relative abundance of microbial root mutualists, and their degree of association with their hosts, also influences plant phenotype and herbivore performance (Garrido et al., 2010; Vannette and Hunter, 2011, 2013; Argüello et al., 2016). The unfortunate result is that, even within a single 
genus of plants, the impacts of microbial root mutualists on tritrophic interactions do not conform to any readily identifiable phylogenetic or life-history pattern (Tao et al., 2015).

The antidote to idiosyncrasy is additional work. Ultimately, phylogenetically-controlled experiments (Reinhart et al., 2012; Vannette et al., 2013) must be combined with realistic ecological treatments of density and diversity (Vannette and Hunter, 2011; Argüello et al., 2016) to establish generality. We will not make progress until we accumulate laboratory and field studies in diverse ecosystems that control phylogeny, identity, density, and environmental conditions of all the interacting partners. These experiments must also measure simultaneously the suite of plant traits that microbial root mutualists influence aboveground. It is increasingly clear that interactions among multiple plant traits will combine to determine the net outcome of tri-trophic interactions aboveground (Tao et al., 2015, 2016).

(2) Similarly, studies of how belowground biota influence tri-trophic interactions above ground are limited currently to a narrow range of natural enemies. Most studies have focused on parasitoids, and we found only four studies on predators and one on insect pathogens. To date, we have no information on effects of soil biota on other key groups of enemies, such as vertebrate predators (e.g., birds, bats, reptiles), insect baculoviruses, or macro-parasites (such as nematodes) that are ubiquitous and economically important across ecosystems. There is no a priori reason to suppose that effects on these groups of enemies should be uncommon. For example, evidence suggests that vertebrate predators can use plant VOCs as foraging cues (Seymour et al., 2010; Amo et al., 2013). Given that some VOC production is mediated by root microbes (above), those microbes may also influence the foraging of vertebrate predators.

Beyond vertebrates, we suggest that interactions among soil biota, plants, herbivores, and pathogens will provide particularly intriguing opportunities for further study. It is now abundantly clear that plant chemistry is a major driver of animal disease across diverse terrestrial ecosystems (de Roode et al., 2013). Plant nutritional and defensive traits influence host quality, host immunity, host behavior, and thereby disease transmission. Given that diverse soil organisms influence plant chemistry above ground (Hunter, 2016), incorporating soil biota more generally in studies of disease spread is vital in placing disease dynamics within a community ecology context (Johnson et al., 2015b).

(3) Another critical missing link is to understand the effects of belowground organisms on interactions among multiple enemies above ground. For example, most of the studies in Table 1 describe the effects of microbial root mutualists on a single species of natural enemy. Yet there is abundant evidence in natural and managed systems of interactions among natural enemies that influence subsequent prey suppression (Cardinale et al., 2003; Johnson et al., 2013; Painter et al., 2015). We might expect that (a) not all enemy species will respond in the same fashion to a given plant trait-change induced by a root mutualist, and (b) multiple phenotypic changes induced simultaneously by root microbes may have differential effects on different enemies. We need detailed experiments, manipulating multiple enemy species simultaneously, to explore effects of microbial root mutualists on herbivore suppression in a community context.

Most intriguing among such interactions may be those between predators and agents of disease. The ecological and evolutionary dynamics of such interactions might be particularly fascinating because predators can have large impacts on disease transmission. Such effects may be density-mediated: for example, by selectively feeding on infected prey, predators can decrease overall parasite transmission (Packer et al., 2003). On the other hand, indirect effects of predators on disease transmission can also be trait-mediated, operating through changes in host behavior, physiology or immune defense. For example, female Trinidadian guppies Poecilia reticulata display strong shoaling tendency in the presence of predators, thereby increasing the transmission of Gyrodactylus parasites (Stephenson et al., 2015). In the snail Lymnaea stagnalis, anti-predator behavior (blood expulsion) reduces their immunocompetence, which also renders them more susceptible to pathogens (Rigby and Jokela, 2000). Critically, the trade-offs between anti-predator and anti-parasite traits can be affected by host resource-availability (Roff and Fairbairn, 2007), and in the case of invertebrate herbivores, the quality of their host plants. Although there has been no direct evidence of host plant quality mediating these traits in herbivores, the trade-offs between anti-predator behavior and growth rate in tobacco hornworms Manduca sexta are more prevalent on well-defended tomato plants (Thaler et al., 2014). Overall, we suggest that it will be particularly informative to link the effects of belowground biota on herbivore densities and traits with the interactions between parasites and predators. We recommend manipulative experiments that vary the densities of infected and uninfected herbivore hosts, in the presence and absence of predators, across a broad range of associations with microbial root mutualists.

(4) Almost all of the mechanisms that we documented above were based on changes in plant chemistry (nutrients, toxins, VOCs) mediated by microbial root mutualists. However, traits such as plant architecture, domatia, trichomes and surface waxes are all subject to influences from soil organisms. These same plant traits mediate predator and parasitoid recruitment and foraging efficiency (Speight et al., 2008), and affect the viability of insect pathogens (Cory and Hoover, 2006). To date, there has been no exploration of the extent to which belowground organisms affect the third trophic level through these critical plant traits. This is particularly important in agricultural systems, where the behavior and persistence of biological control agents determine in part the success of pest management.

(5) Future studies should quantify more thoroughly the effects of belowground organisms on the fitness of all partners in the aboveground tri-trophic interactions. For example, while root colonization by AMF affects the fitness of infected monarch butterflies, parasite growth remains unaffected (Tao et al., 2015). In this case, the effect of belowground organisms on the aboveground tri-trophic interaction would have been missed entirely if only parasite performance had been measured. Because the ecological and evolutionary consequences of species interactions depend on the fitness of all interacting species, we 
urge researchers to quantify as many life history parameters of as many participants as possible.

(6) While a majority of studies has examined these complex interactions uni-directionally from a bottom-up point of view, the third trophic level can also impact plants and soil organisms and create important feedback loops. For example, increases in predation pressure on herbivores that result from mycorrhizal associations can subsequently feedback to increase plant fitness (Hoffmann et al., 2011a). Moreover, effects of root microbial mutualists that first "cascade up" to increase the abundance or efficacy of natural enemies can then "cascade down" again to influence the fitness of plants and their mutualists, as well as the availability of nutrients in soils (Hunter, 2016). Future studies should assess the general frequency and strength of feedback processes that link upper trophic levels aboveground with soil biota below.

(7) By influencing some species more than others, soil organisms can change the structure and composition of herbivore and enemy communities. For example, AMF colonization alters arthropod predator community composition on Deinandra fasciculata (Schreck et al., 2013) and on Glycine max (Ueda et al., 2013). These important studies suggest that we need a community perspective to understand and integrate complex species interactions below- and aboveground.

(8) Abiotic factors, such as nutrient and water availability, strongly regulate the diversity and composition of soil organisms and their interactions with plants (Johnson et al., 2015a). It remains an open and urgent question as to how aboveand belowground multi-trophic interactions are shaped by environmental stresses and global environmental change.

(9) So far, most studies have focused on agricultural systems or model systems. While these provide a starting point for understanding the mechanisms in well-studied and/or

\section{REFERENCES}

Agrawal, A. A. (2000). Mechanisms, ecological consequences and agricultural implications of tri-trophic interactions. Curr. Opin. Plant Biol. 3, 329-335. doi: 10.1016/S1369-5266(00)00089-3

Amo, L., Jansen, J. J., van Dam, N. M., Dicke, M., and Visser, M. E. (2013). Birds exploit herbivore-induced plant volatiles to locate herbivorous prey. Ecol. Lett. 16, 1348-1355. doi: 10.1111/ele.12177

Argüello, A., O’Brien, M. J., van der Heijden, M. G. Wiemken, A., Schmid, B., Niklaus, P. A., et al. (2016). Options of partners improve carbon for phosphorus trade in the arbuscular mycorrhizal mutualism. Ecol. Lett. 19, 648-656. doi: 10.1111/ele.12601

Babikova, Z., Gilbert, L., Bruce, T. J., Birkett, M., Caulfield, J. C., Woodcock, C. et al. (2013). Underground signals carried through common mycelial networks warn neighbouring plants of aphid attack. Ecol. Lett. 16, 835-843. doi: 10.1111/ele.12115

Babikova, Z., Gilbert, L., Randall, K. C., Bruce, T. J., Pickett, J. A., and Johnson, D. (2014). Increasing phosphorus supply is not the mechanism by which arbuscular mycorrhiza increase attractiveness of bean (Vicia faba) to aphids. J. Exp. Bot. 65, 5231-5241. doi: 10.1093/jxb/ eru283

Ballhorn, D. J., Kautz, S., and Schädler, M. (2013). Induced plant defense via volatile production is dependent on rhizobial symbiosis. Oecologia 172, 833-846. doi: $10.1007 / \mathrm{s} 00442-012-2539-\mathrm{x}$ economically important systems, we also need to study systems that are more diverse, such as wild herbs and woody plants, to explore the generality of effects. Even where natural systems have been used, it remains unclear how these interactions play out in the field. For example, in our monarch butterfly studies, we used commercially available mycorrhizal strains, and it remains unclear how natural milkweed-AMF interactions influence interactions aboveground under field conditions (Tao et al., 2015).

In conclusion, it is clear that belowground biota have important effects on aboveground tri-trophic interactions. However, this topic remains in its infancy and many questions remain unresolved. We hope that our review will provide some guidance in designing future studies to better understand interactions between below- and aboveground subsystems of the integrated whole.

\section{AUTHOR CONTRIBUTIONS}

LT and JdR: conceived the idea for the review; LT: conducted the initial literature review; JdR and $\mathrm{MH}$ : provided additional literature to the review. All three authors contributed to writing and editing the manuscript.

\section{ACKNOWLEDGMENTS}

The work was supported by National Science Foundation grants DEB-1257160 and DEB-1256115 to JdR and MH, respectively. We thank members of the Gerardo, Morran, Hickman, and de Roode labs at Emory University for suggestions to improve the manuscript and two reviewers for their helpful comments and suggestions.
Barber, N. A., Kiers, E. T., Hazzard, R. V., and Adler, L. S. (2013). Contextdependency of arbuscular mycorrhizal fungi on plant-insect interactions in an agroecosystem. Front. Plant Sci. 4:338. doi: 10.3389/fpls.2013.00338

Battaglia, D., Bossi, S., Cascone, P., Digilio, M. C., Prieto, J. D., Fanti, P., et al. (2013). Tomato below ground-above ground interactions: Trichoderma longibrachiatum affects the performance of Macrosiphum euphorbiae and its natural antagonists. Mol. Plant Microbe Interact. 26, 1249-1256. doi: 10.1094/MPMI-02-13-0059-R

Bennett, A. E., Bever, J. D., and Deane Bowers, M. (2009). Arbuscular mycorrhizal fungal species suppress inducible plant responses and alter defensive strategies following herbivory. Oecologia 160, 771-779. doi: 10.1007/s00442-009-1338-5

Beyeler, M., and Heyser, W. (1997). The influence of mycorrhizal colonization on growth in the greenhouse and on catechin, epicatechin and procyanidin in roots of Fagus sylvatica L. Mycorrhiza 7, 171-177. doi: 10.1007/s005720050178

Bezemer, T., De Deyn, G., Bossinga, T., Van Dam, N., Harvey, J., and Van der Putten, W. (2005). Soil community composition drives aboveground plant-herbivore-parasitoid interactions. Ecol. Lett. 8, 652-661. doi: 10.1111/j.1461-0248.2005.00762.x

Bezemer, T. M., and van Dam, N. M. (2005). Linking aboveground and belowground interactions via induced plant defenses. Trends Ecol. Evol. 20, 617-624. doi: 10.1016/j.tree.2005.08.006

Borer, E., Seabloom, E., Shurin, J., Anderson, K., Blanchette, C., Broitman, B., et al. (2005). What determines the strength of a trophic cascade? Ecology 86, 528-537. doi: $10.1890 / 03-0816$ 
Brunner, S., Goos, R., Swenson, S., Foster, S., Schatz, B., Lawley, Y., et al. (2015). Impact of nitrogen fixing and plant growth-promoting bacteria on a phloem-feeding soybean herbivore. Appl. Soil Ecol. 86, 71-81. doi: 10.1016/j.apsoil.2014.10.007

Cardinale, B. J., Harvey, C. T., Gross, K., and Ives, A. R. (2003). Biodiversity and biocontrol: emergent impacts of a multi-enemy assemblage on pest suppression and crop yield in an agroecosystem. Ecol. Lett. 6, 857-865. doi: 10.1046/j.1461-0248.2003.00508.x

Chapin, F. S. III., Matson, P. A., and Vitousek, P. (2011). Principles of Terrestrial Ecosystem Ecology. New York, NY: Springer Science \& Business Media.

Cloyd, R. A., and Sadof, C. S. (2000). Effects of plant architecture on the attack rate of Leptomastix dactylopii (Hymenoptera: Encyrtidae), a parasitoid of the citrus mealybug (Homoptera: Pseudococcidae). Environ. Entomol. 29, 535-541. doi: 10.1603/0046-225X-29.3.535

Copetta, A., Lingua, G., and Berta, G. (2006). Effects of three AM fungi on growth, distribution of glandular hairs, and essential oil production in Ocimum basilicum L. var. Genovese. Mycorrhiza 16, 485-494. doi: 10.1007/s00572-006-0065-6

Cory, J. S., and Hoover, K. (2006). Plant-mediated effects in insect-pathogen interactions. Trends Ecol. Evol. 21, 278-286. doi: 10.1016/j.tree.2006.02.005

Cotter, S. C., Simpson, S. J., Raubenheimer, D., and Wilson, K. (2011). Macronutrient balance mediates trade-offs between immune function and life history traits. Funct. Ecol. 25, 186-198. doi: 10.1111/j.1365-2435.2010. 01766.x

Denno, R. F., Gratton, C., Peterson, M. A., Langellotto, G. A., Finke, D. L., and Huberty, A. F. (2002). Bottom-up forces mediate natural-enemy impact in a phytophagous insect community. Ecology 83, 1443-1458. doi: 10.1890/00129658(2002)083[1443:BUFMNE]2.0.CO;2

Der Geest, V. (2000). Can plants use entomopathogens as bodyguards? Ecol. Lett. 3, 228-235. doi: 10.1046/j.1461-0248.2000.00137.x

de Roode, J. C., Lefèvre, T., and Hunter, M. D. (2013). Self-Medication in Animals. Science 340, 150-151. doi: 10.1126/science.1235824

de Roode, J. C., Pedersen, A. B., Hunter, M. D., and Altizer, S. (2008). Host plant species affects virulence in monarch butterfly parasites. J. Anim. Ecol. 77, 120-126. doi: 10.1111/j.1365-2656.2007.01305.x

de Roode, J. C., Rarick, R. M., Mongue, A. J., Gerardo, N. M., and Hunter, M. D. (2011). Aphids indirectly increase virulence and transmission potential of a monarch butterfly parasite by reducing defensive chemistry of a shared food plant. Ecol. Lett. 14, 453-461. doi: 10.1111/j.1461-0248.2011.01604.x

Dicke, M. (1999). "Evolution of induced indirect defense of plants," in The Ecology and Evolution of Induced Defenses, eds R. Tollrian and C. D. Harvell (Princeton, NJ: Princeton University Press), 62-88.

Eigenbrode, S. (2004). The effects of plant epicuticular waxy blooms on attachment and effectiveness of predatory insects. Arthropod Struct. Dev. 33, 91-102. doi: 10.1016/j.asd.2003.11.004

Felton, G. W., and Duffey, S. S. (1990). Inactivation of baculovirus by quinones formed in insect-damaged plant tissues. J. Chem. Ecol. 16, 1221-1236. doi: 10.1007/BF01021021

Fontana, A., Reichelt, M., Hempel, S., Gershenzon, J., and Unsicker, S. B. (2009). The effects of arbuscular mycorrhizal fungi on direct and indirect defense metabolites of Plantago lanceolata L. J. Chem. Ecol. 35, 833-843. doi: 10.1007/s10886-009-9654-0

Fowler, S. V. (1985). Differences in insect species-richness and faunal composition of birch seedlings, saplings and trees: the importance of plant architecture. Ecol. Entomol. 10, 159-169. doi: 10.1111/j.1365-2311.1985.tb00545.x

Francis, R., and Read, D. (1984). Direct transfer of carbon between plants connected by vesicular-arbuscular mycorrhizal mycelium. Nature 307, 53-56. doi: 10.1038/307053a0

Frederickson, M. E., Ravenscraft, A., Miller, G. A., Hernández, L. M. A., Booth, G., and Pierce, N. E. (2012). The direct and ecological costs of an ant-plant symbiosis. Am. Nat. 179, 768-778. doi: 10.1086/665654

Gange, A. C., Brown, V. K., and Aplin, D. M. (2003). Multitrophic links between arbuscular mycorrhizal fungi and insect parasitoids. Ecol. Lett. 6, 1051-1055. doi: 10.1046/j.1461-0248.2003.00540.x

Garmendia, I., Goicoechea, N., and Aguirreolea, J. (2004). Effectiveness of three Glomus species in protecting pepper (Capsicum annuum L.) against verticillium wilt. Biol. Control 31, 296-305. doi: 10.1016/j.biocontrol.2004.04.015
Garrido, E., Bennett, A. E., Fornoni, J., and Strauss, S. Y. (2010). Variation in arbuscular mycorrhizal fungi colonization modifies the expression of tolerance to above-ground defoliation. J. Ecol. 98, 43-49. doi: 10.1111/j.1365-2745.2009.01586.x

Gassmann, A. J., Stock, S. P., Tabashnik, B. E., and Singer, M. S. (2010). Tritrophic effects of host plants on an herbivore-pathogen interaction. Ann. Entomol. Soc. Am. 103, 371-378. doi: 10.1603/AN09130

Gehring, C., and Bennett, A. (2009). Mycorrhizal fungal-plant-insect interactions: the importance of a community approach. Environ. Entomol. 38, 93-102. doi: 10.1603/022.038.0111

Gingras, D., and Boivin, G. (2002). Effect of plant structure, host density and foraging duration on host finding by Trichogramma evanescens (Hymenoptera: Trichogrammatidae). Environ. Entomol. 31, 1153-1157. doi: 10.1603/0046-225X-31.6.1153

Godschalx, A. L., Schädler, M., Trisel, J. A., Balkan, M. A., and Ballhorn, D. J. (2015). Ants are less attracted to the extrafloral nectar of plants with symbiotic, nitrogen-fixing rhizobia. Ecology 96, 348-354. doi: 10.1890/14-1178.1

Goicoechea, N., Merino, S., and Sánchez-Díaz, M. (2004). Contribution of arbuscular mycorrhizal fungi (AMF) to the adaptations exhibited by the deciduous shrub Anthyllis cytisoides L. under water deficit. Physiol. Plant. 122, 453-464. doi: 10.1111/j.1399-3054.2004.00421.x

Gols, R., and Harvey, J. A. (2009). Plant-mediated effects in the Brassicaceae on the performance and behaviour of parasitoids. Phytochem. Rev. 8, 187-206. doi: 10.1007/s11101-008-9104-6

Gowler, C. D., Leon, K. E., Hunter, M. D., and de Roode, J. C. (2015). Secondary defense chemicals in milkweed reduce parasite infection in monarch butterflies, Danaus plexippus. J. Chem. Ecol. 41, 520-523. doi: 10.1007/s10886-015-0586-6

Grman, E. (2012). Plant species differ in their ability to reduce allocation to non-beneficial arbuscular mycorrhizal fungi. Ecology 93, 711-718. doi: 10.1890/11-1358.1

Grman, E., and Robinson, T. M. (2012). Resource availability and imbalance affect plant-mycorrhizal interactions: a field test of three hypotheses. Ecology 94 62-71. doi: 10.1890/12-0385.1

Guerrieri, E., Lingua, G., Digilio, M. C., Massa, N., and Berta, G. (2004). Do interactions between plant roots and the rhizosphere affect parasitoid behaviour? Ecol. Entomol. 29, 753-756. doi: 10.1111/j.0307-6946.2004.00644.x

Haviola, S., Kapari, L., Ossipov, V., Rantala, M. J., Ruuhola, T., and Haukioja, E. (2007). Foliar phenolics are differently associated with Epirrita autumnata growth and immunocompetence. J. Chem. Ecol. 33, 1013-1023. doi: 10.1007/s10886-007-9271-8

Heath, K. D., and Tiffin, P. (2007). Context dependence in the coevolution of plant and rhizobial mutualists. Proc. R. Soc. B Biol. Sci. 274, 1905-1912. doi: $10.1098 /$ rspb.2007.0495

Heil, M. (2015). Extrafloral nectar at the plant-insect interface: a spotlight on chemical ecology, phenotypic plasticity, and food webs. Annu. Rev. Entomol. 60, 213-232. doi: 10.1146/annurev-ento-010814-020753

Heil, M., Hilpert, A., Fiala, B., and Linsenmair, K. E. (2001). Nutrient availability and indirect (biotic) defence in a Malaysian ant-plant. Oecologia 126, 404-408. doi: $10.1007 / \mathrm{s} 004420000534$

Hempel, S., Stein, C., Unsicker, S. B., Renker, C., Auge, H., Weisser, W. W. et al. (2009). Specific bottom-up effects of arbuscular mycorrhizal fungi across a plant-herbivore-parasitoid system. Oecologia 160, 267-277. doi: 10.1007/s00442-009-1294-0

Hoffmann, D., Vierheilig, H., Peneder, S., and Schausberger, P. (2011a). Mycorrhiza modulates aboveground tri-trophic interactions to the fitness benefit of its host plant. Ecol. Entomol. 36, 574-581. doi: $10.1111 /$ j.1365-2311.2011.01298

Hoffmann, D., Vierheilig, H., Riegler, P., and Schausberger, P. (2009). Arbuscular mycorrhizal symbiosis increases host plant acceptance and population growth rates of the two-spotted spider mite Tetranychus urticae. Oecologia 158, 663-671. doi: 10.1007/s00442-008-1179-7

Hoffmann, D., Vierheilig, H., and Schausberger, P. (2011b). Arbuscular mycorrhiza enhances preference of ovipositing predatory mites for direct prey-related cues. Physiol. Entomol. 36, 90-95.doi: 10.1111/j.1365-3032.2010.00751.x

Hoffmann, D., Vierheilig, H., and Schausberger, P. (2011c). Mycorrhiza-induced trophic cascade enhances fitness and population growth of an acarine predator. Oecologia 166, 141-149. doi: 10.1007/s00442-010-1821-z 
Holland, J. N., Chamberlain, S. A., and Horn, K. C. (2009). Optimal defence theory predicts investment in extrafloral nectar resources in an ant-plant mutualism. J. Ecol. 97, 89-96. doi: 10.1111/j.1365-2745.2008.01446.x

Hunter, M. D. (2016). The Phytochemical Landscape. Linking Trophic Interactions and Nutrient Dynamics. Princeton, NJ: Princeton University Press.

Hunter, M. D., and Price, P. W. (1992). Playing chutes and ladders: heterogeneity and the relative roles of bottom-up and top-down forces in natural communities. Ecology 73, 724-732.

Hunter-Fujita, F. R., Entwistle, P. F., Evans, H. F., and Crook, N. E. (1998). Insect Viruses and Pest Management. Chichester, UK: John Wiley \& Sons Ltd.

Jaber, L. R., and Vidal, S. (2010). Fungal endophyte negative effects on herbivory are enhanced on intact plants and maintained in a subsequent generation. Ecol. Entomol. 35, 25-36. doi: 10.1111/j.1365-2311.2009.01152.x

Jallow, M. F., Dugassa-Gobena, D., and Vidal, S. (2008). Influence of an endophytic fungus on host plant selection by a polyphagous moth via volatile spectrum changes. Arthropod Plant Interact. 2, 53-62. doi: 10.1007/s11829-008-9033-8

Johnson, N. C., Wilson, G. W., Wilson, J. A., Miller, R. M., and Bowker, M. A. (2015a). Mycorrhizal phenotypes and the law of the minimum. New Phytol. 205, 1473-1484. doi: 10.1111/nph.13172

Johnson, P. T., de Roode, J. C., and Fenton, A. (2015b). Why infectious disease research needs community ecology. Science 349:1259504. doi: 10.1126/science.1259504

Johnson, P. T., Preston, D. L., Hoverman, J. T., and LaFonte, B. E. (2013). Host and parasite diversity jointly control disease risk in complex communities. Proc. Natl. Acad. Sci. U. S.A. 110, 16916-16921. doi: 10.1073/pnas.1310557110

Johnson, S. N., Lopaticki, G., Barnett, K., Facey, S. L., Powell, J. R., and Hartley, S. E. (2015c). An insect ecosystem engineer alleviates drought stress in plants without increasing plant susceptibility to an above-ground herbivore. Funct. Ecol. 30, 894-902. doi: 10.1111/1365-2435.12582

Johnson, S. N., Staley, J. T., McLeod, F. A., and Hartley, S. E. (2011). Plant-mediated effects of soil invertebrates and summer drought on above-ground multitrophic interactions. J. Ecol. 99, 57-65. doi: 10.1111/j.1365-2745.2010.01748.x

Katayama, N., Zhang, Z. Q., and Ohgushi, T. (2011). Community-wide effects of below-ground rhizobia on above-ground arthropods. Ecol. Entomol. 36, 43-51. doi: $10.1111 / j .1365-2311.2010 .01242 . x$

Kennedy, G. G. (2003). Tomato, pests, parasitoids, and predators: tritrophic interactions involving the genus Lycopersicon. Annu. Rev. Entomol. 48, 51-72. doi: 10.1146/annurev.ento.48.091801.112733

Kos, M., Houshyani, B., Wietsma, R., Kabouw, P., Vet, L. E., van Loon, J. J., et al. (2012). Effects of glucosinolates on a generalist and specialist leafchewing herbivore and an associated parasitoid. Phytochemistry 77, 162-170. doi: 10.1016/j.phytochem.2012.01.005

Krimmel, B. A., and Pearse, I. (2013). Sticky plant traps insects to enhance indirect defence. Ecol. Lett. 16, 219-224. doi: 10.1111/ele.12032

Krips, O., Kleijn, P., Willems, P., Gols, G., and Dicke, M. (1999). Leaf hairs influence searching efficiency and predation rate of the predatory mite Phytoseiulus persimilis (Acari: Phytoseiidae). Exp. Appl. Acarol. 23, 119-131. doi: 10.1023/A:1006098410165

Kruidhof, H. M., de Rijk, M., Hoffmann, D., Harvey, J. A., Vet, L. E., and Soler, R. (2013). Effect of belowground herbivory on parasitoid associative learning of plant odours. Oikos 122, 1094-1100. doi: 10.1111/j.1600-0706.2012.00142.x

Kula, A., and Hartnett, D. (2015). Effects of mycorrhizal symbiosis on aboveground arthropod herbivory in tallgrass prairie: an in situ experiment. Plant Ecol. 216, 589-597. doi: 10.1007/s11258-015-0461-0

Laird, R. A., and Addicott, J. F. (2007). Arbuscular mycorrhizal fungi reduce the construction of extrafloral nectaries in Vicia faba. Oecologia 152, 541-551. doi: 10.1007/s00442-007-0676-4

Lampert, E. (2012). Influences of plant traits on immune responses of specialist and generalist herbivores. Insects 3, 573-592. doi: 10.3390/insects3020573

Lampert, E. C., Dyer, L. A., and Bowers, M. D. (2011). Chemical defense across three trophic levels: Catalpa bignonioides, the caterpillar Ceratomia catalpae, and its endoparasitoid Cotesia congregata. J. Chem. Ecol. 37, 1063-1070. doi: 10.1007/s10886-011-0018-1

Lawton, J. H. (1983). Plant architecture and the diversity of phytophagous insects. Annu. Rev. Entomol. 28, 23-29. doi: 10.1146/annurev.en.28.010183.000323

Leitner, M., Kaiser, R., Hause, B., Boland, W., and Mithöfer, A. (2010). Does mycorrhization influence herbivore-induced volatile emission in Medicago truncatula? Mycorrhiza 20, 89-101. doi: 10.1007/s00572-009-0264-z
Low, P. A. McArthur, C., Fisher, K., and Hochuli, D. F. (2014). Elevated volatile concentrations in high-nutrient plants: do insect herbivores pay a high price for good food? Ecol. Entomol. 39, 480-491. doi: 10.1111/een.12124

Masters, G. J., Jones, T. H., and Rogers, M. (2001). Host-plant mediated effects of root herbivory on insect seed predators and their parasitoids. Oecologia 127, 246-250. doi: $10.1007 / \mathrm{s} 004420000569$

Maure, F., Thomas, F., Doyon, J., and Brodeur, J. (2016). Host nutritional status mediates degree of parasitoid virulence. Oikos 125, 1314-1323. doi: $10.1111 /$ oik.02944

Megías, A. G., and Müller, C. (2010). Root herbivores and detritivores shape aboveground multitrophic assemblage through plant-mediated effects. J. Anim. Ecol. 79, 923-931. doi: 10.1111/j.1365-2656.2010.01681.x

Moon, D. C., Barnouti, J., and Younginger, B. (2013). Context-dependent effects of mycorrhizae on herbivore density and parasitism in a tritrophic coastal study system. Ecol. Entomol. 38, 31-39. doi: 10.1111/j.1365-2311.2012.01399.x

Nishida, R. (2002). Sequestration of defensive substances from plants by Lepidoptera. Annu. Rev. Entomol. 47, 57-92. doi: 10.1146/annurev.ento.47.091201.145121

Packer, C., Holt, R. D., Hudson, P. J., Lafferty, K. D., and Dobson, A. P. (2003). Keeping the herds healthy and alert: implications of predator control for infectious disease. Ecol. Lett. 6, 797-802. doi: 10.1046/j.1461-0248.2003.00500.x

Painter, L. E., Beschta, R. L., Larsen, E. J., and Ripple, W. J. (2015). Recovering aspen follow changing elk dynamics in Yellowstone: evidence of a trophic cascade? Ecology 96, 252-263. doi: 10.1890/14-0712.1

Pangesti, N., Weldegergis, B. T., Langendorf, B., van Loon, J. J., Dicke, M., and Pineda, A. (2015). Rhizobacterial colonization of roots modulates plant volatile emission and enhances the attraction of a parasitoid wasp to host-infested plants. Oecologia 178, 1169-1180. doi: 10.1007/s00442-015-3277-7

Parker, B. J., Elderd, B. D., and Dwyer, G. (2010). Host behaviour and exposure risk in an insect-pathogen interaction. J. Anim. Ecol. 79, 863-870. doi: 10.1111/j.1365-2656.2010.01690.x

Pineda, A., Dicke, M., Pieterse, C. M., and Pozo, M. J. (2013a). Beneficial microbes in a changing environment: are they always helping plants to deal with insects? Funct. Ecol. 27, 574-586. doi: 10.1111/1365-2435.12050

Pineda, A., Soler, R., Weldegergis, B. T., Shimwela, M. M., Van Loon, J. J., and Dicke, M. (2013b). Non-pathogenic rhizobacteria interfere with the attraction of parasitoids to aphid-induced plant volatiles via jasmonic acid signalling. Plant Cell Environ. 36, 393-404. doi: 10.1111/j.1365-3040.2012.02581.x

Polis, G. A., Sears, A. L., Huxel, G. R., Strong, D. R., and Maron, J. (2000). When is a trophic cascade a trophic cascade? Trends Ecol. Evol. 15, 473-475. doi: 10.1016/S0169-5347(00)01971-6

Povey, S., Cotter, S. C., Simpson, S. J., Lee, K. P., and Wilson, K. (2009). Can the protein costs of bacterial resistance be offset by altered feeding behaviour? J. Anim. Ecol. 78, 437-446. doi: 10.1111/j.1365-2656.2008.01499.xy

Price, P. W., Bouton, C. E., Gross, P., McPheron, B. A., Thompson, J. N., and Weis, A. E. (1980). Interactions among three trophic levels: influence of plants on interactions between insect herbivores and natural enemies. Annu. Rev. Ecol. Syst. 11, 41-65. doi: 10.1146/annurev.es.11.110180.000353

Radhika, V., Kost, C., Bartram, S., Heil, M., and Boland, W. (2008). Testing the optimal defence hypothesis for two indirect defences: extrafloral nectar and volatile organic compounds. Planta 228, 449-457. doi: 10.1007/s00425-008-0749-6

Rapparini, F., Llusià, J., and Peñuelas, J. (2008). Effect of arbuscular mycorrhizal (AM) colonization on terpene emission and content of Artemisia annua $\mathrm{L}$. Plant Biol. 10, 108-122. doi: 10.1055/s-2007-964963

Rasmann, S., Bennett, A., Biere, A., Karley, A., and Guerrieri, E. (2017). Root symbionts: powerful drivers of plant above- and belowground indirect defenses. Insect Sci. 24, 947-960. doi: 10.1111/1744-7917.12464

Reinhart, K. O., Wilson, G. W., and Rinella, M. J. (2012). Predicting plant responses to mycorrhizae: integrating evolutionary history and plant traits. Ecol. Lett. 15, 689-695. doi: 10.1111/j.1461-0248.2012.01786.x

Reudler, J. H., Biere, A., Harvey, J. A., and van Nouhuys, S. (2011). Differential performance of a specialist and two generalist herbivores and their parasitoids on Plantago lanceolata. J. Chem. Ecol. 37, 765-778. doi: 10.1007/s10886-011-9983-7

Rigby, M. C., and Jokela, J. (2000). Predator avoidance and immune defence: costs and trade-offs in snails. Proc. R. Soc. Lond. Series B Biol. Sci. 267, 171-176. doi: $10.1098 /$ rspb.2000.0983 
Rodríguez, A., San Andrés, V., Cervera, M., Redondo, A., Alquézar, B., Shimada, T., et al. (2011). The monoterpene limonene in orange peels attracts pests and microorganisms. Plant Signal. Behav. 6, 1820-1823. doi: $10.4161 /$ psb.6.11.16980

Roff, D. A., and Fairbairn, D. J. (2007). The evolution of trade-offs: where are we? J. Evol. Biol. 20, 433-447. doi: 10.1111/j.1420-9101.2006.01255.x

Schädler, M., and Ballhorn, D. J. (2016). Beneficial soil microbiota as mediators of the plant defensive phenotype and aboveground plant-herbivore interactions. Prog. Bot. 78, 305-343. doi: 10.1007/124_2016_13

Schausberger, P., Peneder, S., Juerschik, S., and Hoffmann, D. (2012). Mycorrhiza changes plant volatiles to attract spider mite enemies. Funct. Ecol. 26, 441-449. doi: 10.1111/j.1365-2435.2011.01947.x

Schreck, T. K., David, S. J., and Mooney, K. A. (2013). Effects of Brassica nigra and plant-fungi interactions on the arthropod community of Deinandra fasciculata. Biol. Invasions 15, 2443-2454. doi: 10.1007/s10530-013-0464-5

Seymour, J. R., Simó, R., Ahmed, T., and Stocker, R. (2010). Chemoattraction to dimethylsulfoniopropionate throughout the marine microbial food web. Science 329, 342-345. doi: 10.1126/science.1188418

Silliman, B. R., and Bertness, M. D. (2002). A trophic cascade regulates salt marsh primary production. Proc. Natl. Acad. Sci. 99, 10500-10505. doi: $10.1073 /$ pnas.162366599

Smilanich, A. M., Dyer, L. A., Chambers, J. Q., and Bowers, M. D. (2009). Immunological cost of chemical defence and the evolution of herbivore diet breadth. Ecol. Lett. 12, 612-621. doi: 10.1111/j.1461-0248.2009.01309.x

Smith, S. E., and Read, D. J. (2008). Mycorrhizal Symbiosis, 3rd Edn. San Diego, CA: Academic Press.

Soler, R., Bezemer, T., Van Der Putten, W. H., Vet, L. E., and Harvey, J. A. (2005). Root herbivore effects on above-ground herbivore, parasitoid and hyperparasitoid performance via changes in plant quality. J. Anim. Ecol. 74, 1121-1130. doi: 10.1111/j.1365-2656.2005.01006.x

Soler, R., Harvey, J. A., Kamp, A. F., Vet, L. E., Van der Putten, W. H., Martijn Bezemer, T. et al. (2007a). Root herbivores influence the behaviour of an aboveground parasitoid through changes in plant-volatile signals. Oikos 116, 367-376. doi: 10.1111/j.0030-1299.2007.15501.x

Soler, R., Harvey, J. A., Rouchet, R., Schaper, S. V., and Martijn Bezemer, T. (2010). Impacts of belowground herbivory on oviposition decisions in two congeneric butterfly species. Entomol. Exp. Appl. 136, 191-198. doi: 10.1111/j.1570-7458.2010.01015.x

Soler, R., Harvey, J., and Bezemer, T. (2007b). Foraging efficiency of a parasitoid of a leaf herbivore is influenced by root herbivory on neighbouring plants. Funct. Ecol. 21, 969-974.doi: 10.1111/j.1365-2435.2007.01309.x

Song, Y. Y., Zeng, R. S., Xu, J. F., Li, J., Shen, X., and Yihdego, W. G. (2010). Interplant communication of tomato plants through underground common mycorrhizal networks. PLoS ONE 5:e13324. doi: 10.1371/journal.pone.0013324

Speight, M. R., Hunter, M. D., and Watt, A. D. (2008). Ecology of Insects: Concepts and Applications, 2nd Edn. Chichester, UK: Wiley-Blackwell.

Stephenson, J. F., van Oosterhout, C., Mohammed, R. S., and Cable, J. (2015). Parasites of Trinidadian guppies: evidence for sex- and agespecific trait-mediated indirect effects of predators. Ecology 96, 489-498. doi: 10.1890/14-0495.1

Sternberg, E. D., Lefèvre, T., Li, J., de Castillejo, C. L., Li, H., Hunter, M. D., et al. (2012). Food plant derived disease tolerance and resistance in a natural butterfly-plant-parasite interactions. Evolution 66, 3367-3376. doi: 10.1111/j.1558-5646.2012.01693.x

Symondson, W., Sunderland, K., and Greenstone, M. (2002). Can generalist predators be effective biocontrol agents? 1. Annu. Rev. Entomol. 47, 561-594. doi: 10.1146/annurev.ento.47.091201.145240

Tao, L., Ahmad, A., de Roode, J. C., and Hunter, M. D. (2016). Arbuscular mycorrhizal fungi affect plant tolerance and chemical defences to herbivory through different mechanisms. J. Ecol. 104, 561-571. doi: 10.1111/1365-2745.12535

Tao, L., Berns, A. R., and Hunter, M. D. (2014). Why does a good thing become too much? Interactions between foliar nutrients and toxins determine performance of an insect herbivore. Funct. Ecol. 28, 190-196. doi: 10.1111/1365-2435.12163
Tao, L., Gowler, C. D., Ahmad, A., Hunter, M. D., and de Roode, J. C. (2015). Disease ecology across soil boundaries: effects of below-ground fungi on above-ground host-parasite interactions. Proc. R. Soc. B 282:20151993. doi: 10.1098/rspb.2015.1993

Tao, L., and Hunter, M. D. (2012). Does anthropogenic nitrogen deposition induce phosphorus limitation in herbivorous insects? Glob. Chang. Biol. 18, 1843-1853. doi: 10.1111/j.1365-2486.2012.02645.x

Thaler, J. S., Contreras, H., and Davidowitz, G. (2014). Effects of predation risk and plant resistance on Manduca sexta caterpillar feeding behaviour and physiology. Ecol. Entomol. 39, 210-216. doi: 10.1111/een.12086

Ueda, K., Tawaraya, K., Murayama, H., Sato, S., Nishizawa, T., Toyomasu, T., et al. (2013). Effects of arbuscular mycorrhizal fungi on the abundance of foliar-feeding insects and their natural enemy. Appl. Entomol. Zool. 48, 79-85. doi: $10.1007 /$ s13355-012-0155-1

van der Heijden, M. G. A., Klironomos, J. N., Ursic, M., Moutoglis, P., StreitwolfEngel, R., Sanders, I. R., et al. (1998). Mycorrhizal fungal diversity determines plant biodiversity, ecosystem variability and productivity. Nature 396, 69-72. doi: $10.1038 / 23932$

Van der Putten, W. H., Vet, L. E., Harvey, J. A., and Wäckers, F. L. (2001). Linking above-and belowground multitrophic interactions of plants, herbivores, pathogens, and their antagonists. Trends Ecol. Evol. 16, 547-554. doi: 10.1016/S0169-5347(01)02265-0

Vannette, R. L., and Hunter, M. D. (2011). Plant defence theory re-examined: nonlinear expectations based on the costs and benefits of resource mutualisms. J. Ecol. 99, 66-76. doi: 10.1111/j.1365-2745.2010.01755.x

Vannette, R. L., and Hunter, M. D. (2013). Mycorrhizal abundance affects the expression of plant resistance traits and herbivore performance. J. Ecol. 101, 1019-1029. doi: 10.1111/1365-2745.12111

Vannette, R. L., Hunter, M. D., and Rasmann, S. (2013). Arbuscular mycorrhizal fungi alter above- and below-ground chemical defense expression differentially among Asclepias species. Front. Plant Sci. 4:361. doi: 10.3389/fpls.2013.00361

Vannette, R. L., and Rasmann, S. (2012). Arbuscular mycorrhizal fungi mediate below-ground plant-herbivore interactions: a phylogenetic study. Funct. Ecol. 26, 1033-1042. doi: 10.1111/j.1365-2435.2012.02046.x

Vet, L. E., and Dicke, M. (1992). Ecology of infochemical use by natural enemies in a tritrophic context. Annu. Rev. Entomol. 37, 141-172. doi: 10.1146/annurev.en.37.010192.001041

Wardle, D. A., Bardgett, R. D., Klironomos, J. N., Setälä, H., van Der Putten, W. H., and Wall, D. H. (2004). Ecological linkages between aboveground and belowground biota. Science 304, 1629-1633. doi: 10.1126/science.1094875

Wei, J.-R., Yang, Z.-Q., Hao, H.-L., and, Du, J.-W. (2008). (R)-(+)-limonene, kairomone for Dastarcus helophoroides, a natural enemy of longhorned beetles. Agric. For. Entomol. 10, 323-330. doi: 10.1111/j.1461-9563.2008.00384.x

Wooley, S. C., and Paine, T. D. (2011). Infection by mycorrhizal fungi increases natural enemy abundance on tobacco (Nicotiana rustica). Environ. Entomol. 40, 36-41. doi: 10.1603/EN10145

Wurst, S., and Jones, T. H. (2003). Indirect effects of earthworms (Aporrectodea caliginosa) on an above-ground tritrophic interaction. Pedobiologia 47, 91-97. doi: 10.1078/0031-4056-00173

Wyckhuys, K. A. G., Graziosi, I., Burra, D. D., and Walter, A. J. (2017). Phytoplasma infection of a tropical root crop triggers bottom-up cascades by favoring generalist over specialist herbivores. PLOS ONE 12:e0182766. doi: 10.1371/journal.pone.0182766

Conflict of Interest Statement: The authors declare that the research was conducted in the absence of any commercial or financial relationships that could be construed as a potential conflict of interest.

Copyright (c) 2017 Tao, Hunter and de Roode. This is an open-access article distributed under the terms of the Creative Commons Attribution License (CC BY). The use, distribution or reproduction in other forums is permitted, provided the original author(s) or licensor are credited and that the original publication in this journal is cited, in accordance with accepted academic practice. No use, distribution or reproduction is permitted which does not comply with these terms. 